PREPARED FOR THE U.S. DEPARTMENT OF ENERGY, UNDER CONTRACT DE-AC02-76CH03073

PPPL-3742

PPPL-3742

UC-70

Comment on "Generation of Electromagnetic Pulses from Plasma Channels Induced by Femtosecond Light Strings"

by

Gennady Shvets, Igor Kaganovich, and Edward Startsev

September 2002

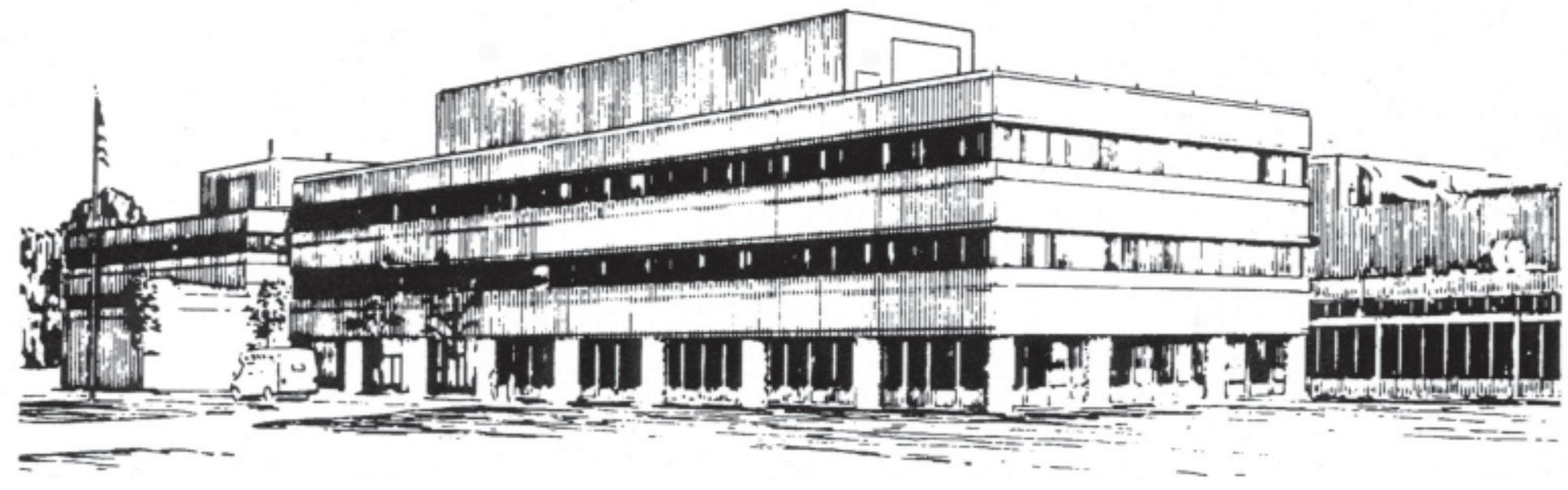

PRINCETON PLASMA PHYSICS LABORATORY PRINCETON UNIVERSITY, PRINCETON, NEW JERSEY 


\section{PPPL Reports Disclaimer}

This report was prepared as an account of work sponsored by an agency of the United States Government. Neither the United States Government nor any agency thereof, nor any of their employees, makes any warranty, express or implied, or assumes any legal liability or responsibility for the accuracy, completeness, or usefulness of any information, apparatus, product, or process disclosed, or represents that its use would not infringe privately owned rights. Reference herein to any specific commercial product, process, or service by trade name, trademark, manufacturer, or otherwise, does not necessarily constitute or imply its endorsement, recommendation, or favoring by the United States Government or any agency thereof. The views and opinions of authors expressed herein do not necessarily state or reflect those of the United States Government or any agency thereof.

\section{Availability}

This report is posted on the U.S. Department of Energy's Princeton Plasma Physics Laboratory Publications and Reports web site in Fiscal Year 2002. The home page for PPPL Reports and Publications is: http://www.pppl.gov/pub_report/

DOE and DOE Contractors can obtain copies of this report from:

U.S. Department of Energy

Office of Scientific and Technical Information

DOE Technical Information Services (DTIS)

P.O. Box 62

Oak Ridge, TN 37831

Telephone: (865) 576-8401

Fax: (865) 576-5728

Email: reports@adonis.osti.gov

This report is available to the general public from:

National Technical Information Service

U.S. Department of Commerce

5285 Port Royal Road

Springfield, VA 22161

Telephone: 1-800-553-6847 or

(703) 605-6000

Fax: (703) 321-8547

Internet: http://www.ntis.gov/ordering.htm 


\title{
Comment on "Generation of Electromagnetic Pulses from Plasma Channels Induced by Femtosecond Light Strings"
}

\author{
Gennady Shvets, Igor Kaganovich, and Edward Startsev \\ Princeton Plasma Physics Laboratory, Princeton University, Princeton, NJ 08543
}

In a recent Letter [1], Cheng et. al. calculated/predicted several new effects: that (a) fraction of the short laser pulse momentum can be imparted to plasma electrons via collisional damping of the laser, thereby exciting a long-lived (longer than an oscillation period) plasma wave, which (b) gives rise to a spatially uniform dipole moment of a plasma, which (c) emits farfield narrow-band radiation at the plasma frequency $\omega_{p}$ over the recombination time of the plasma. We claim that the calculation of the effect (a) is in error and the predicted effects (b,c) do not occur as described. In fact, predicted narrow-band emission at $\omega_{p}$ would not occur even if the momentum transfer and the dipole excitation were calculated correctly.

(a) Cheng et. al. calculated that an electron absorbing laser radiation due to collisions at a rate $\gamma$ is displaced by a distance $\xi_{0}$, given by Eq. (8), which does not depend on $\gamma$ because it is proportional to the product of the gained momentum $(\propto \gamma$, according to Eq. (7)) and the drift time $T \approx \gamma^{-1}$. This argument holds only if there is no restoring force $-\omega_{p}^{2} \xi$ from the plasma ions over this period of time. Because the restoring force can only be neglected for $t \ll \omega_{p}^{-1}$, the calculation of Cheng et. al. is valid only if $\gamma \gg \omega_{p}$. For such highly collisional plasmas it is not sensible to talk about plasma oscillations since they decay within less than one period (or about a picosecond for the chosen plasma density) due to electron-neutral collisions. This contradicts the authors' claim that the duration of the plasma oscillations is limited by the plasma recombination.

Plasma oscillations can last longer than one period if $\gamma \ll \omega_{p}$, but the oscillation amplitude is reduced from that given by the authors by a factor $\gamma / \omega_{p}$. For example, for $\gamma=3 \times 10^{11} \mathrm{~s}^{-1}$ (which corresponds to one undamped plasma oscillation), the correct displacement of the plasma electron by the radiation pressure force $F_{\mathrm{RP}}$ is a factor 6 smaller than claimed by Cheng et. al. . In other words, under no circumstances can the plasma oscillations with amplitude $\xi_{0}$ and lifetime $>\omega_{p}^{-1}$ be excited via collisional absorption force $F_{\mathrm{RP}}$ given by Eq. (7). Moreover, Cheng et. al. overlooked the usual ponderomotive force $F_{P}=-\frac{e^{2}}{2 m \omega_{L}^{2}} \partial_{z}\left|E_{L}\right|^{2}=\frac{e^{2}}{2 m \omega_{L}^{2} v_{g}} \partial_{t}\left|E_{L}\right|^{2}$ because they used an approximate relation between electric and magnetic fields. When collisions are negligible $F_{P} \gg F_{\mathrm{RP}}$ and $\xi_{0}^{\mathrm{P}}=\left(e^{2} / 2 m^{2} c \omega_{L}^{2}\right) \int_{-\infty}^{+\infty} d t\left|E_{L}\right|^{2}[2]$. The authors' claim that the usual ponderomotive force (which is pro- portional to the spatial intensity gradient) is too small for light strings of $100 \mu \mathrm{m}$ diameter and centimeter length is wrong: the spatial gradient that matters in this case is inversely proportional to the short pulse length $c t_{p} \approx 3 \mu \mathrm{m}$.

(b) Cheng et. al. incorrectly assumed that all plasma electrons oscillate in phase regardless of their position $z$, so that $\dot{\xi}(t, z) \equiv \dot{\xi}(t)$ is a function of time only, producing a uniform current $J_{z}$. This can only happen if the plasma oscillations are excited instantaneously by the laser pulse propagating with an infinite speed. In fact, plasma oscillations are set up by the laser pulse at different times $t=z / v_{g}$, where $v_{g}<c$ is the group velocity of the pulse. Therefore, $\dot{\xi}(t, z) \equiv \dot{\xi}\left(t-z / v_{g}\right)$, and the longitudinal wavenumber of the current perturbation with frequency $\omega_{\text {osc }}$ is $k_{z}=\omega_{\text {osc }} / v_{g}$. For $L=1 \mathrm{~cm}$ long plasma filament this translates into the phase difference of $\Delta \phi=\omega_{p} L / c \approx 60$ for plasma oscillations excited along the light string. The destructive interference of these oscillations will surely destroy the radiation conjectured by Cheng et. al.

(c) The idea of using a laser-driven plasma filament for radiation generation using the setup of Ref. [1] is erroneous for two reasons. First, it is impossible to produce far-field radiation by creating an excitation which moves uniformly with a subluminal speed $v_{g}<c$. Indeed, for electromagnetic radiation in free space $k_{\perp}^{2}=$ $\omega_{\text {osc }}^{2} / c^{2}-k_{z}^{2}<0$, and radiation does not propagate out of the plasma channel.

Second, even if the long-wavelength $\left(k_{z} \approx 0\right)$ displacement $\xi_{0}$ of a plasma column envisioned by Cheng et. al. could be set up somehow, it still would not emit narrow-bandwidth radiation at $\omega=\omega_{p}$. Plasma waves can never emit radiation at $\omega_{\mathrm{osc}}=\omega_{p}$ because the displacement current $(1 / 4 \pi) \partial_{t} \vec{E}_{p}$ (where $\vec{E}_{p}$ is electric field of a plasma wave) exactly compensates the plasma current - en $\vec{v}$ prohibiting radiation. While Cherenkov-like radiation is possible when the velocity of the laser pulse exceeds that of the emitted radiation, and was even experimentally observed in electrooptic materials [3], it is not narrow-bandwidth.

Moreover, 2-D oscillations of a narrow plasma column differ substantially $[4,5]$ from the simplified $1-\mathrm{D}$ case considered by the authors. Cheng et. al. erroneously predicted the far-field radiation because Eq. (11) contains a prescribed current $J_{z}$ which is not calculated selfconsistently: the effect of $\vec{E}_{\mathrm{rad}}$ on the electron motion was neglected. By inserting the prescribed current $J_{z}$ into Eq. (11) Cheng et. al. demonstrated that, not sur- 
prisingly, a driven electron current emits radiation. This not the same as demonstrating that an initially perturbed plasma filament emits radiation while executing a selfconsistent plasma oscillation.

This research was supported by the U.S. Department of Energy.

[1] C.-C. Cheng, E. M. Wright, and J. V. Moloney, Phys. Rev. Lett. 87, 213001 (2001).
[2] J. M. Rax and N. J. Fisch, Phys. Fluids B, 4, 1323 (1992).

[3] D. Auston et. al., Phys. Rev. Lett. 53, 1555 (1984); D. H. Auston and M. C. Nuss, IEEE J. Quant. Electronics QE-24, 184 (1988).

[4] N. A. Krall and A. W. Trivelpiece, Principles of Plasma Physics, Chapt. 4 (McGraw-Hill, New York, 1973).

[5] G. Shvets and X. Li, Phys. Plasmas 6, 591 (1999). 


\section{External Distribution}

Plasma Research Laboratory, Australian National University, Australia

Professor I.R. J ones, Flinders University, Australia

Professor J oão Canalle, Instituto de Fisica DEQ/IF - UERJ , Brazil

Mr. Gerson O. Ludwig, Instituto Nacional de Pesquisas, Brazil

Dr. P.H. Sakanaka, Instituto Fisica, Brazil

The Librarian, Culham Laboratory, England

Library, R61, Rutherford Appleton Laboratory, England

Mrs. S.A. Hutchinson, JET Library, England

Professor M.N. Bussac, Ecole Polytechnique, France

Librarian, Max-Planck-Institut für Plasmaphysik, Germany

J olan Moldvai, Reports Library, MTA KFKI-ATKI, Hungary

Dr. P. Kaw, Institute for Plasma Research, India

Ms. P.J . Pathak, Librarian, Insitute for Plasma Research, India

Ms. Clelia De Palo, Associazione EURATOM-ENEA, I taly

Dr. G. Grosso, Instituto di Fisica del Plasma, Italy

Librarian, Naka Fusion Research Establishment, J AERI, J apan

Library, Plasma Physics Laboratory, Kyoto University, J apan

Research Information Center, National Institute for Fusion Science, J apan

Dr. O. Mitarai, Kyushu Tokai University, J apan

Library, Academia Sinica, Institute of Plasma Physics, People's Republic of China

Shih-Tung Tsai, Institute of Physics, Chinese Academy of Sciences, People's Republic of China

Dr. S. Mirnov, TRINITI, Troitsk, Russian Federation, Russia

Dr. V.S. Strelkov, Kurchatov Institute, Russian Federation, Russia

Professor Peter Lukac, Katedra Fyziky Plazmy MFF UK, Mlynska dolina F-2, Komenskeho Univerzita, SK-842 15 Bratislava, Slovakia

Dr. G.S. Lee, Korea Basic Science Institute, South Korea

Mr. Dennis Bruggink, Fusion Library, University of Wisconsin, USA

Institute for Plasma Research, University of Maryland, USA

Librarian, Fusion Energy Division, Oak Ridge National Laboratory, USA

Librarian, Institute of Fusion Studies, University of Texas, USA

Librarian, Magnetic Fusion Program, Lawrence Livermore National Laboratory, USA

Library, General Atomics, USA

Plasma Physics Group, Fusion Energy Research Program, University of California at San Diego, USA

Plasma Physics Library, Columbia University, USA

Alkesh Punjabi, Center for Fusion Research and Training, Hampton University, USA

Dr. W.M. Stacey, Fusion Research Center, Georgia Institute of Technology, USA

Dr. J ohn Willis, U.S. Department of Energy, Office of Fusion Energy Sciences, USA

Mr. Paul H. Wright, Indianapolis, Indiana, USA 
The Princeton Plasma Physics Laboratory is operated by Princeton University under contract with the U.S. Department of Energy.

\author{
Information Services \\ Princeton Plasma Physics Laboratory \\ P.O. Box 451 \\ Princeton, NJ 08543
}

Phone: 609-243-2750

Fax: 609-243-2751

e-mail: pppl_info@pppl.gov

Internet Address: http://www.pppl.gov 